\title{
Deciphering boulder mobility and erosion from cosmogenic nuclide exposure dating
}

\author{
Benjamin H. Mackey ${ }^{1,2}$ and Michael P. Lamb ${ }^{1}$ \\ Received 24 July 2012; revised 14 January 2013; accepted 24 January 2013; published 6 March 2013.
}

[1] Large boulders are prominent features in many geomorphic systems and are frequently targeted for cosmogenic exposure dating. Presently, there are little data or theory predicting exposure age, erosion rate, and mobilization frequency of boulders in environments such as channels, talus slopes, or moraines. Here we explore the potential for cosmogenic isotope analysis to constrain the transport and erosion history of boulders. Through a series of numerical experiments, we model the statistical evolution of nuclide concentrations around the surface of boulders. Stable boulders have distinctive radial distributions of surface concentration in comparison to those that are periodically mobile, and this can be used to establish boulder stability. Mean nuclide accumulation rates around the surface of an eroding boulder increase when the radius is smaller than approximately $1.5 e$-folding lengths $(\sim 1.2 \mathrm{~m})$ of neutron flux intensity, whereupon nuclide accumulation on the underside of the boulder becomes non-negligible $(\sim 10 \%)$. Model results for cases of no cosmogenic inheritance and uniform erosion indicate the normalized standard deviation of nuclide surface concentration systematically decreases with increasing number of boulder mobilization events. This may be used to constrain the minimum number of times a boulder has moved for up to approximately four events, or distinguish between rarely and frequently mobilized boulders. Using non-dimensional scaling relations between surface concentration statistics, boulder size, and time, we propose methods to estimate the minimum age, frequency of movement, and erosion rate of mobile boulders with application to a range of geomorphic problems.

Citation: Mackey, B. H., and M. P. Lamb (2013), Deciphering boulder mobility and erosion from cosmogenic nuclide exposure dating, J. Geophys. Res. Earth Surf., 118, 184-197, doi:10.1002/jgrf.20035.

\section{Introduction}

[2] Boulders are prominent geomorphic features in many landscapes, including steep river channels, glacial moraines, alluvial fans, and outburst-flood deposits. In the fluvial environment, for example, many steep channels are lined with boulders which can affect flow hydraulics, impound bedload, and set the rate of bedrock incision [Montgomery et al., 1996; Seidl et al., 1997; Howard, 1998; Sklar and Dietrich, 1998; Lamb, Dietrich and Sklar, 2008; Johnson et al., 2009; Lamb and Fonstad, 2010], which in turn sets the pace for landscape evolution [e.g., Wolman and Miller, 1960; Molnar and England, 1990; Blum and Tornqvist, 2000; Whipple, 2004]. On the practical side, there is a growing appreciation of the habitat that boulders create, both directly, where collections of boulders form hiding areas for fish during

\footnotetext{
${ }^{1}$ Division of Geological and Planetary Sciences, California Institute of Technology, Pasadena, California, USA.

${ }^{2}$ Department of Geological Sciences, University of Canterbury, Christchurch, New Zealand.

Corresponding author: B. H. Mackey, Department of Geological Sciences, University of Canterbury, Private Bag 4800, Christchurch, New Zealand. (ben.mackey@canterbury.ac.nz)

(C)2013. American Geophysical Union. All Rights Reserved. 2169-9003/13/10.1002/jgrf.20035
}

high flows, and indirectly, by causing the deposition of gravel suitable for spawning [Kondolf and Wolman, 1993; Buffington et al., 2004]. When mobilized by floods or debris flows, boulders can present a major hazard to people and infrastructure [Eaton, 1935; Costa, 1983].

[3] A large body of research has been undertaken on the mobility of smaller sediment (gravel and finer) [e.g., Parker and Klingeman, 1982; van Rijn, 1984; Johnston et al., 1998; Schmeeckle et al., 2007; Yager et al., 2007; Nelson et al., 2009], yet comparatively little is known about the behavior of boulders in channels. This knowledge gap is attributable to limited data and theory relating to the stability and erosion rate of boulders in fluvial systems [Carling, 1983; Costa, 1983; Carling et al., 2002; Lamb, Dietrich and Venditti, 2008; Carretier and Regard, 2011]; large boulders rarely move, and, if they do, it is problematic and dangerous to attempt measurements. Consequently, fundamental questions about the behavior of boulders in channels remain largely unresolved. These include the frequency of boulder mobilization (e.g., by floods, debris flows, or undermining), how quickly boulders can erode in place by abrasion, weathering and comminution [Schumm and Stevens, 1973; Seidl et al., 1994; Howard, 1998; Carretier and Regard, 2011], and ultimately, how long large boulders persist in channels. The scarce data that are available from fluvial systems indicate that boulder exposure ages can be as much as $10^{4}$ to $>10^{5}$ years [Wohl, 1992; Seidl 
et al., 1994; Seidl et al., 1997], yet there are no data constraining long-term mobilization frequency, or framed alternatively, the timeframe of long-term boulder stability.

[4] Given the apparent stability of boulders in comparison to smaller particles [Seidl et al., 1997], boulders are commonly targeted for cosmogenic exposure dating in order to constrain the age of a landform. Thus far, cosmogenic dating has been used to establish primarily the timing of boulder emplacement, rather than an event recurrence interval or boulder erosion rate. The dominant application has been dating boulders in moraines [e.g., Hallet and Putkonen, 1994; Douglass et al., 2006; Briner, 2009; Heyman et al., 2011]. Other applications focus on quantifying the age of geomorphic features including boulders deposited from paleo-outburst flooding [Cerling et al., 1994; Aciego et al., 2007; Lamb, et al., 2008; Amidon and Farley, 2011], debris flow deposits [Putnam et al., 2010], abandoned alluvial fan surfaces [Ritz et al., 1995; Frankel et al., 2007; Behr et al., 2010], terraces [Vassallo et al., 2007], shorelines [Rogers et al., 2012], and balanced rocks [Stirling and Anooshehpoor, 2006; Balco et al., 2011]. In these applications, boulders are presumed to be the most stable feature in the environment and suitable for exposure age dating, although the key assumption of stability is rarely tested. Movement (e.g., boulder sliding or rotation) or postdepositional erosion or shielding is generally seen as detrimental to sample selection and actively avoided [Cerling and Craig, 1994; Gosse and Phillips, 2001].

[5] Here we propose a theoretical framework and undertake numerical experiments to determine whether the transport and erosion history of large boulders can be determined via cosmogenic nuclide dating around boulder surfaces. Our approach builds on recent numerical experiments of Mackey and Lamb [2010] and Carretier and Regard [2011] who were the first to model nuclide concentrations in mobile, eroding terrestrial boulders. We focus our analysis on large, meter-scale boulders, for cases where hillslope inheritance is negligible (e.g., due to boulders sourced from deep-seated landslides), and impose a condition of uniform erosion. We ask whether boulder residence time, comminution rate, and frequency of movement can be determined from patterns of cosmogenic nuclide exposure about the surface of a single clast. Specifically, we explore the potential for terrestrial cosmogenic nuclides to determine (1) the residence time and erosion rate of boulders, (2) whether a boulder is stable or mobile, and (3) if mobile, the frequency of mobilization. First, we present our model goals and a numerical model to simulate the accumulation of cosmogenic nuclides in a mobile boulder. Second, we explore how the evolution of nuclides in boulders varies with radius, erosion rate, and mobilization. Third, we use dimensional analysis to develop generalized relations for nuclide accumulation in boulders that can be applied to wide range of parameter space (e.g., erosion rates, boulder size, rock densities, and nuclide production rates). Care is taken to make the model formulation generic so that results may apply to a wide range of geomorphic settings (e.g., channels, moraines and talus slopes).

\section{Model Goals and Application}

[6] As discussed above, boulders are often targeted for cosmogenic dating under the common assumptions that (1) boulders are relatively stable and (2) boulders may have minimal inheritance from hillslopes prior to being deposited [Swanson and Caffee, 2001; Putkonen and Swanson, 2003; Heyman et al., 2011; Vassallo et al., 2011]. For example, Lamb, et al. [2008] made both of these assumptions to constrain the age of canyon formation from a large flood event. Inheritance was assumed negligible as boulders likely were derived from deep-seated rock failures and, given the size of failures, the probability is low that the boulders sampled happened to reside prior to failure within the zone of high cosmogenic exposure (approximately top $1.5 \mathrm{~m}$ of the Earth's surface). Additional processes conveying boulders with minimal inheritance to channel systems include deepseated landslides [e.g., Kelsey, 1978] and rockslides [e.g., Putnam et al., 2010]. Some environments have been documented to show boulders in regolith with exposure concentrations that reflect this inheritance, such as granitic hillslopes in the northern Sierra Nevada range [Granger et al., 2001] and desert catchments in Mongolia [e.g., Vassallo et al., 2007; Vassallo et al., 2011]. However, in many landscapes, mobile regolith and shallow landslides are devoid of boulders in the meter-size range [e.g., Marshall and Sklar, 2012], suggesting that boulders are sourced from plucking in-channel or from deep-seated (bedrock) hillslope failures. In steep, tectonically active landscapes, mobile regolith is often less than $\sim 1 \mathrm{~m}$ in thickness [DiBiase et al., 2010; Heimsath et al., 2012] meaning that boulders that are substantially larger than this must, by definition, be generated by deep seated processes. It is these environments we focus on here.

[7] Most previous applications of cosmogenic nuclide dating of mobile sediment in river channels have focused on sand-sized particles where transport in fluvial systems is generally fast compared to residence times in immobile and mobile regolith [Granger et al., 1996]. The cosmogenic nuclide concentrations of sand sampled from streams are typically thought to record the (inherited) signal from hillslopes rather than processes active in fluvial channels. This is probably a reasonable assumption as finer-grained particles are abundant in mobile regolith and can be rapidly transported in fluvial systems [e.g., Repka et al., 1997; Carretier et al., 2009; Schmidt et al., 2011]. In contrast, large boulders commonly sourced from deep-seated landslides and rockfall may have minimal hillslope exposure and relatively long residence times in channels [Seidl et al., 1997; Schmidt et al., 2011], where they may only move by debris flows, rare flood events, or they may erode in place [Schumm and Stevens, 1973]. Carretier and Regard [2011] recently explored the intermediate case of decimeter-scale grains delivered to channels from shallow landslides or regolith creep (they did not consider deep-seated landslides) with both hillslope and channel processes playing a role in the pattern of nuclide concentration around a boulder. In particular, they assessed whether downstream modification of the inherited hillslope signal can be used to determine clast transport and erosion rate. Herein we build on the approach of Carretier and Regard [2011], as well as our preliminary work [Mackey and Lamb, 2010], and explore whether boulder residence time, frequency of movement (or non-movement), and erosion rate can be determined from analysis of a single large (>meter-scale) boulder at a site (rather than downstream variations in nuclide exposure as in Carretier and Regard [2011]). 
[8] There are many factors that can complicate interpretation of cosmogenic nuclide dating, most of which have not been explored in numerical modeling of mobile, eroding boulders [Mackey and Lamb, 2010; Carretier and Regard, 2011]. Therefore, it is sensible to start with as simple of model as possible that still incorporates the dominant processes at work. If even the simplest case exposes unconstrained parameters or the need for overly exhaustive sampling campaigns, more complicated cases may be intractable in application, at least given the measurement techniques available today. Given our inability to answer this question based on current understanding, numerical modeling, rather than brute-force sampling, is warranted. With this in mind, we explore several boulder transport and exposure scenarios and attempt to cast the results in a generic, dimensionless framework so that results may be used for a wide range of scenarios including different sediment sizes, nuclide production rates, boulder erosion rates, particle densities and for application to landforms such as river channels, alluvial fans, moraines, and talus slopes.

[9] Following previous work [Mackey and Lamb, 2010; Carretier and Regard, 2011], we assume spherical particles that erode uniformly and steadily in the radial direction and that rotate about a preferred axis. The assumption of a given particle geometry affects the model nuclide exposure calculation because locations in the interior of the boulder are shielded by the boulder itself (i.e., self-shielding). A spherical geometry is reasonable for many boulders in nature, this assumption allows comparison to previous numerical and analytical work [Lal and Chen, 2005], and Carretier and Regard [2011] found that using a parallelepiped rather than a sphere had a relatively small effect $(\sim 20 \%)$ on their results. The spherical assumption is not realistic, however, for particle rolling kinematics. While more realistic non-spherical shapes are unlikely to affect the self-shielding calculation, such particles do tend to roll about a preferred axis [Sneed and Folk, 1958; Ehlmann et al., 2008; Turowski et al., 2009], which we assume here.

[10] We explore scenarios where boulder movement events occur at a given frequency (e.g., a flood with a given recurrence interval). In this way, the nuclide concentrations we are modeling are tracking regular periods of boulder stability (i.e., when the bulk of nuclide exposure occurs). Distinguishing short periods of high frequency (e.g., annual) movement events within longer-term (e.g., $\sim 10^{4}$ year) cycles of movement and stability is not possible with the techniques modeled herein. We neglect intermittent burial, which remains relatively unconstrained [Yager et al., 2012], and may be a more significant issue than inheritance in some cases [Heyman et al., 2011].

[11] The rate of erosion of boulders over long timescales is unknown (and is one of the independent variables we explore), and therefore a steady and uniform radial erosion rate is assumed as a reasonable starting place. Work on smaller clasts that erode during fluvial transport indicates that erosion rate and grain size are nonlinearly related, with erosion rate decreasing with smaller sizes in a Sternberg-type exponential relationship [Kodama, 1994; Attal and Lavé, 2009]. However there are no data or theory suggesting this relationship applies to larger boulders (e.g., $>1 \mathrm{~m}$ diameter) in channels, which may erode in debris flows or in place [Whipple et al., 2000]. Moreover, boulder erosion within moraines or during rock fall on talus slopes may not follow these relationships. Thus, we decouple erosion rate from movement frequency and sediment size, treat these as three independent parameters, and explore model sensitivity to these variables.

[12] Finally, we focus on stable nuclides, as opposed to radionuclides such as ${ }^{10} \mathrm{Be}$. Our model results may be applicable to radionuclides if boulder residence time is short compared to the nuclide half-life. For boulders with much longer residence times, nuclide decay needs to be taken into account [Lal and Chen, 2005]. Analysis of stable nuclides, such as cosmogenic ${ }^{3} \mathrm{He}$ in olivine, is a promising technique for boulder dating as stable nuclides can track exposure ages over long time scales, and mineral separation techniques and concentration measurements (i.e., noble gas mass spectrometry) are less labor intensive and costly than for radiogenic isotopes [Gosse and Phillips, 2001; Dunai, 2010]. Given our finding that $\sim 10$ samples per boulder must be collected to gain a meaningful result on boulder transport (section 3 ), stable nuclides offer a more tractable strategy than their radioactive brethren. As a result of focusing on stable nuclides, we adopt basalt as an example rock, given that phenocrysts in basalt (e.g., olivine, pyroxene) are common targets for stable cosmogenic nuclide exposure dating [e.g., Kurz, 1986; Margerison et al., 2005; Blard and Farley, 2008; Gayer et al., 2008; Dunai, 2010]. We use an intermediate density of $2.5 \mathrm{~g} / \mathrm{cm}^{3}$, reflecting the potential density variation in basalt due to vesicularity [Licciardi et al., 1999; Gayer et al., 2008; Goehring et al., 2010]. Stable nuclides do pose problems related to the presence of non-cosmogenic sources of the nuclide of interest, such as from mantle-derived inclusions or nucleogenic production over time, but there are approaches to quantify this non-cosmogenic component [e.g., Margerison et al., 2005; Blard and Farley, 2008; Amidon and Farley, 2011]. We also show a dimensionless framework that allows results to be applied to any rock density (section 5).

\section{Numerical Formulation}

[13] Cosmic ray penetration into rock at the Earth's surface is most simply framed from the perspective of an infinitely flat surface exposed to the full unobstructed view of the sky (i.e., no topographic shielding). The in situ production rate of cosmogenic nuclides decreases approximately exponentially with vertical depth from the rock surface [Lal, 1991] with apparent $e$-folding or attenuation depths of about 0.55 to $0.8 \mathrm{~m}$ in most rocks [Gosse and Phillips, 2001]. Earlier theoretical and modeling work has quantified the effects of geometric shape (spheres, cubes, and inclined or vertical surfaces) on production rates within a stable target rock [Dunne et al., 1999; Masarik and Wieler, 2003; Lal and Chen, 2005]. Beyond the work of Carretier and Regard [2011], the closest widely studied analog to a mobile, eroding boulder accumulating cosmogenic nuclides is meteoroids [e.g., Graf et al., 1990; Bhandari et al., 1993], although nuclide production dynamics in space are significantly different than those at the Earth's surface [Lal, 1995].

[14] To approximate the accumulation of cosmogenic nuclides within a boulder, we modify the approach of $\mathrm{Lal}$ and Chen [2005], who modeled the production of cosmogenic nuclides in a range of geometric target bodies, including stable 
spherical boulders. Our model is based upon a circular disc of nodes within a sphere as illustrated in Figures 1 and 2, which accumulate cosmogenic nuclides based on their position in the 3 -D boulder relative to incoming individual cosmic rays. The disc of target nodes would be equivalent to the $B$ - $C$ axial plane of an elliptical-shaped boulder that rotates about the $A$ axis. Each node is targeted with cosmic rays equally distributed about the upper hemisphere using a 3-D coordinate system, where $\theta$ is the horizontal distribution $(0-2 \pi)$, and $\varphi$ deviation from the vertical $(0-\pi / 2)$ (Figure 1$)$. The boulder is assumed to be sitting on a horizontal plane (Figure 1); burial of a small lower portion of the boulder within the sediment bed would not significantly change the model results (e.g., Figure 2) because the lower parts of boulders are mostly self-shielded, and the unshielded ray paths are sub-horizontal with substantially smaller flux intensity as compared to vertical ray paths, as described below.

[15] The intensity of each ray as it reaches a node within the boulder is governed by the effective particle flux at the boulder surface $(F)$ and the distance the ray must travel through the boulder $(L)$ (Figure 1). Vertical cosmic rays pass through less of the Earth's atmosphere than rays arriving obliquely, and therefore cosmic ray intensity is a function of angular deviation from vertical $(\varphi)$, such that the effective flux at the surface of the boulder is

$$
F(\varphi)=F_{0} \cos ^{m}(\varphi)
$$

where $m=2.3$ and $F_{0}$ is full intensity (e.g., for a ray traveling vertically, $F_{0}=F(\varphi=0)$ ) [Nishiizumi et al., 1989; Lal, 1991; Gosse and Phillips, 2001].

[16] The intensity of the cosmic ray neutron flux further decreases as it passes through the rock mass due to neutron spallation, scattering, and absorption [Nishiizumi et al., 1989; Lal, 1991]. The mass attenuation coefficient, $\Lambda\left(\mathrm{g} / \mathrm{cm}^{2}\right)$, is the mass equivalent through which the flux intensity decays exponentially (the $e$-folding length scale). As we are modeling individual rays, we adopt a value of $208 \mathrm{~g} / \mathrm{cm}^{2}$ for true attenuation length [Gosse and Phillips, 2001; Balco et al., 2011], which equates to $83 \mathrm{~cm}$ in rock of density $2.5 \mathrm{~g} / \mathrm{cm}^{3}$. This is approximately 1.3 times greater than the apparent attenuation length generally used to describe vertical attenuation through a flat surface $\left(160 \mathrm{~g} / \mathrm{cm}^{2}\right)$, which integrates flux coming from all angles [Dunai, 2010]. The relative production rate $(P)$ of stable cosmogenic nuclides (e.g., $\left.{ }^{3} \mathrm{He}\right)$ at a given point within the boulder is therefore [Gosse and Phillips, 2001]:

$$
P(r, \varphi, \theta)=\int_{\theta=0}^{2 \pi} \int_{\varphi=0}^{\pi / 2} F(\varphi) \sin (\varphi) e^{-\frac{L(r, \varphi, \theta)}{2 *}} d \varphi d \theta
$$

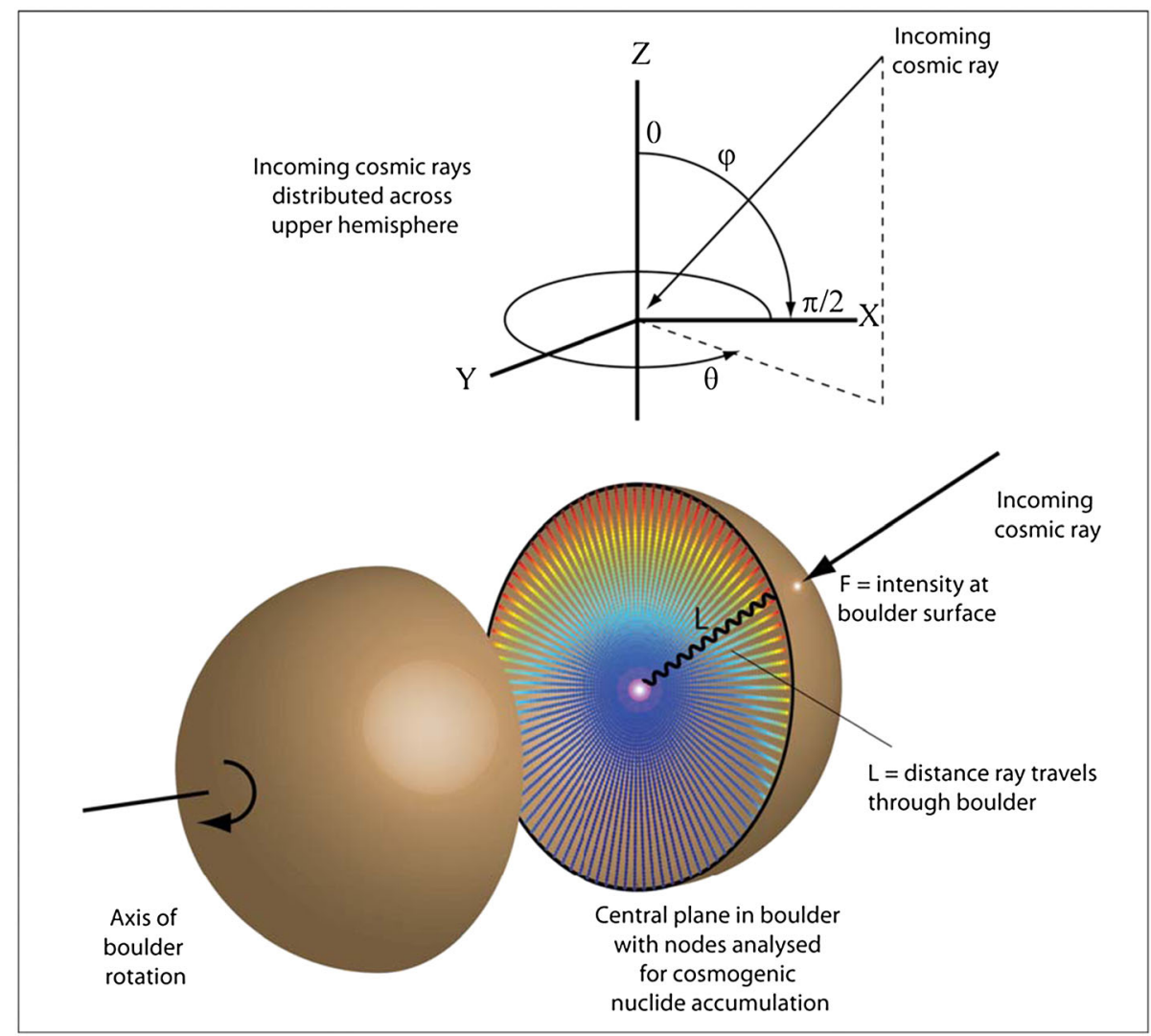

Figure 1. The model consists of nodes on a vertical plane within a spherical boulder. Cosmic rays target each node from the upper hemisphere. Boulder movement is simulated by rolling the boulder about an axis orthogonal to the plane. A ray is shown hitting the boulder surface, and then passing through the rock mass a distance $(L)$ before hitting a node in the center of the boulder. The boulder is assumed to rest on a horizontal surface (i.e., no burial). 
(a)

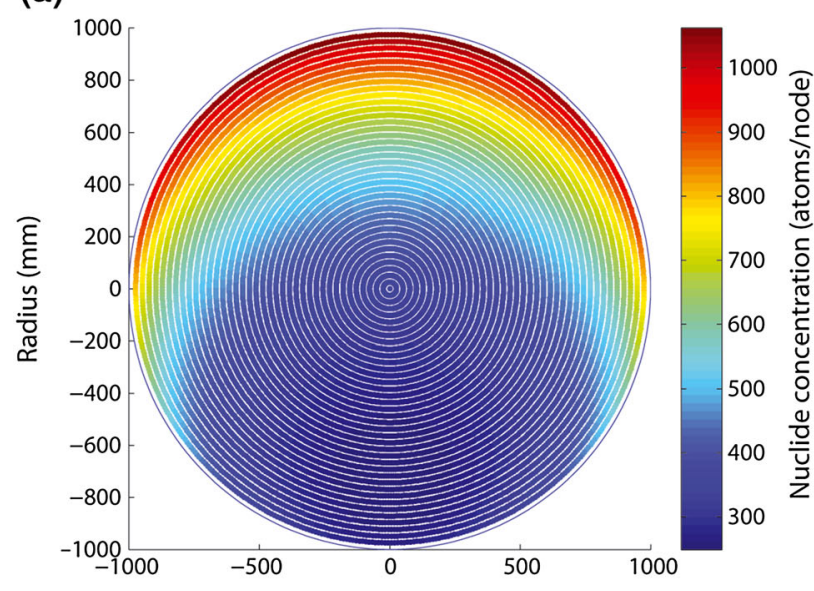

(b)

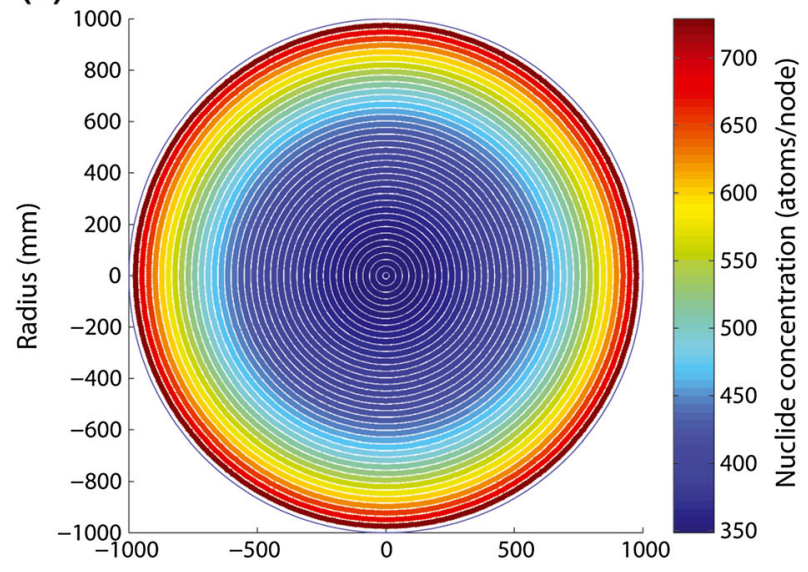

Figure 2. Two meter diameter boulder exposed to cosmic rays for 1000 years. (a) Stable boulder showing maximum nuclide concentration on upper boulder surface, reducing with distance into the boulder. (b) Boulder that has also been exposed for 1000 years, but rolled 20 times. Concentration of nuclides is more evenly distributed around the boulder.

where $z^{*}$ is the neutron intensity decay e-folding length $(\Lambda / \rho)$, $\rho$ is the density of rock, and $r$ is the radial coordinate. As described by Gosse and Phillips [2001], $\sin (\varphi)$ in equation (2) is to account for the convergence of the spherical coordinate system. We assume no shielding other than self-shielding by the boulder of interest. The concentration of nuclides $(C)$ at a node within a stable boulder over time $(t)$ is therefore

$$
C(r, \varphi, \theta, t)=\int_{t=0}^{t} \int_{\theta=0}^{2 \pi} \int_{\varphi=0}^{\pi / 2} F(\varphi) \sin (\varphi) e^{-\frac{L(r, \varphi, \theta)}{2 *}} d \varphi d \theta d t
$$

[17] For each node on the disc within the spherical boulder at position $r$, we integrate the ray intensity of all incoming rays during each time step. We scale concentrations within the boulder to a reference concentration of 1 atom/node/yr for an unshielded horizontal surface. This is achieved by multiplying the integrated nuclide concentration at each node at each time step by 0.5254 . This ratio converts the full upper hemisphere distribution of rays with $F_{0}=1$ to a more useful reference unit, based on comparison with

$$
P_{\text {max }}=\frac{2 \pi F_{0}}{m+1}
$$

where $P_{\max }$ is the full flux through a horizontal surface [Gosse and Phillips, 2001]. Nodes partially shielded within the boulder receive some fraction of 1 atom for each year of run time governed by the degree of shielding by the rock mass. Concentrations in model runs can therefore be scaled to the production rate of the stable nuclide of interest.

[18] Production rates on the upper surface of stable boulders have a small dependence on boulder diameter, with smaller boulders having slightly lower production rates than large boulders due to particle leakage from missing mass effects [Masarik et al., 2000; Masarik and Wieler, 2003]. This means that the top of a small boulder will have a slightly lower nuclide production rate than a flat surface, as it does not receive the secondary nuclide cascade created in the missing-mass above the shoulder of the boulder, although we did not account for this in our modeling.

[19] To verify the numerical model, we tested results against Lal and Chen [2005] who derived analytical solutions for vertical and horizontal radial lines from the center of a spherical boulder. We performed a series of simulations with different numerical discretizations and found that a distribution of 12 rays with constant radial spacing in the $\theta$ coordinate (i.e., $d \theta=\pi / 6$ ) and 20 rays in the $\varphi$ coordinate (i.e., $d \varphi=\pi / 40$ ) matched the theoretical curves of Lal and Chen [2005] to within $1 \%$ (mostly $<0.1 \%)$. This numerical discretization is adopted here.

[20] In addition, we ran a series of numerical simulations to determine the number of nodes that need to be accounted for about the boulder to accurately capture the true statistics of nuclide concentrations. Using a $5 \mathrm{~m}$ radius stable boulder, we discretize the nodes about the circumference of the disc at the boulder center and found that 10 evenly spaced nodes (i.e., $\pi / 5$ spacing in radians) reflect the minimum number of evenly spaced samples required to capture the true statistics of nuclide concentrations within 5\% error (Figure 3). This suggests that $\sim 10$ samples are needed to perform similar statistics in the field. Here we adopt 10 nodes about the disc perimeter for numerical efficiency; nodes in the radial direction are spaced at $25 \mathrm{~mm}$.

[21] To simulate a boulder movement event (e.g., a flood), we rotate the boulder through a random angle about an axis orthogonal to the 2-D plane which contains the nodes to be analyzed (Figure 1). Each node retains its previous nuclide concentration, but the production rate at each node following movement will change to reflect the new position relative to incoming rays based on self-shielding and the reduced boulder radius due to erosion. Erosion is achieved by systematically removing nodes on the outside of the boulder at increments not exceeding $25 \mathrm{~mm}$, at intervals dependent on the proscribed erosion rate. This value is a compromise between computational efficiency and removing too great a thickness of the high nuclide concentrations in the outer few centimeters [e.g., Muzikar, 2008], a possibility if boulder erosion only occurred during movement events. In our simulations, where the radius is calculated to erode by more than $25 \mathrm{~mm}$ between rolls, erosion is assessed incrementally between rolls. Model results are therefore applicable to cases of continuous erosion, or cases of event-based erosion with $<25 \mathrm{~mm}$ of erosion per movement event. By varying the initial radius $\left(R_{0}\right)$, erosion 


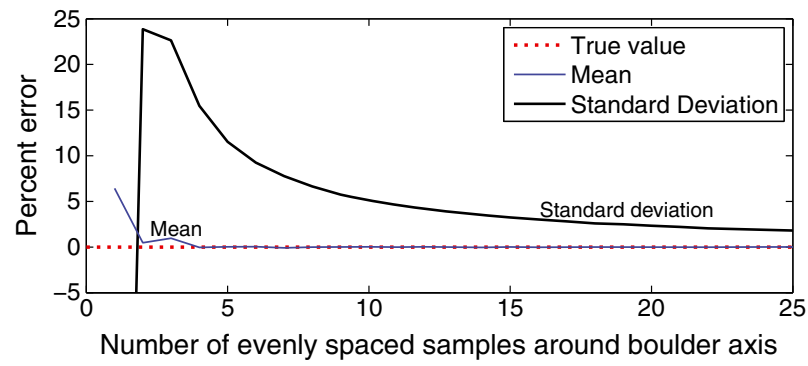

Figure 3. Simulation of the number of equally spaced samples taken around the circumference of a boulder required to capture the true mean and standard deviation. Plots reflect the number of samples taken around a $5 \mathrm{~m}$ radius stable boulder (i.e., a case with high variance between the upper and lower surface). Measured mean converges within approximately three samples on the true mean whereas the standard deviation is within 5\% error after 10 samples.

rate $(E)$, characteristic recurrence interval of boulder movement $\left(r_{T}\right.$, i.e., the inverse of movement frequency), and total exposure time $\left(t_{T}\right)$, we explore the parameter space of nuclide accumulation for a range of simplified boulder transport and erosion scenarios.

\section{Model Results}

[22] In this section of the paper, we first compare the modeled characteristics of nuclides in stable and mobile boulders. Then we present the evolution of nuclides on the surface of boulders of varying size undergoing different erosion rates, followed by the evolution of nuclide concentration about the margin of periodically mobile boulders. In section 5 , we cast the results in a non-dimensional framework to develop more general relations between nuclide concentration and boulder history.

[23] As shown by others [Masarik and Wieler, 2003; Lal and Chen, 2005; Balco et al., 2011; Carretier and Regard, 2011], the distribution of nuclide concentrations through a stable boulder is predictable. Figure 2a shows a $2 \mathrm{~m}$ diameter boulder exposed for 1000 years, with the upper surface accumulating the highest concentrations of cosmogenic isotopes. Nuclide concentrations decline exponentially with vertical depth through the boulder, and surface concentrations decline with radial distance from the upper surface of the boulder. Both of these trends vary systematically depending on boulder size (Figure 4). The underside of a stable boulder has the lowest concentration of nuclides, as it is mostly selfshielded by the overlying rock, with this effect greatest in larger boulders (Figure 4a). In contrast, Figure $2 \mathrm{~b}$ shows a boulder that has been mobilized (rolled through a random angle) 20 times over the same 1000 year period as Figure 2a. The concentration of nuclides is more evenly distributed around the margin of the boulder than the stable case, as different surfaces of the boulder face are intermittently exposed to the full intensity of cosmic rays. The maximum nuclide concentration around the surface of the eroded boulder (Figure $2 b$ ) is lower than the stable one (Figure 2a), due to rotation exposing different faces of the boulder upright.

[24] The trends in Figure 2 are more clearly illustrated in Figure 5 where the statistics of nuclide concentration about the boulder's outer surface are tracked over time for a $5 \mathrm{~m}$ radius boulder eroding at a constant rate $(E=0.05 \mathrm{~mm} / \mathrm{yr})$, and undergoing $10(n=10)$ rolling events at a regular occurrence $\left(r_{T}=10,000\right.$ years). As the boulder erodes, mean nuclide concentration around the margin initially exhibits similar behavior to the evolution of nuclides on a flat surface [e.g., Cerling and Craig, 1994], increasing rapidly before approaching an approximate steady state condition, whereupon erosion nearly balances production and the rate of nuclide increase is slow. As the boulder radius $(R)$ decreases below $1.2 \mathrm{~m}$ $\left(\sim 1.5\right.$ true $e$-folding lengths $\left.\left(z^{*}\right)\right)$, the production rate of nuclides on the boulder underside is $\sim 15 \%$ that on the upper surface (Figure 4c). The rate of accumulation of nuclides around the boulder surface continues to increase exponentially as the radius approaches zero. The variation of nuclide concentration around the boulder surface (shown by standard deviation) is variable, depending on the amount of boulder rotation, but systematically decreases at smaller radii. Between rolls, the standard deviation around the boulder (a)

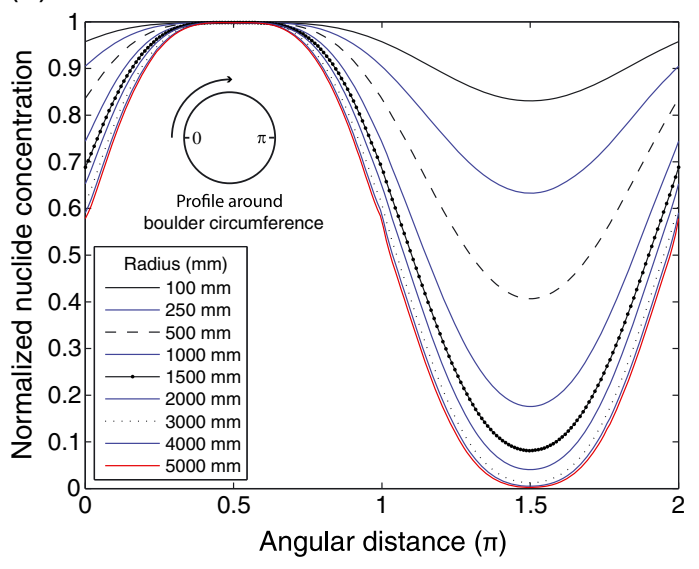

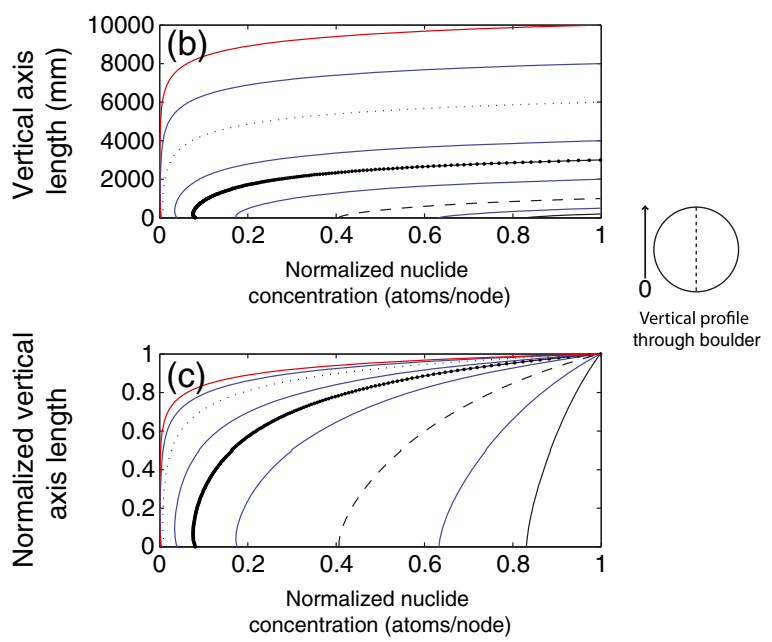

Figure 4. (a) Transects of nuclide concentrations around the margin of boulders of different sizes. (b) Transect of nuclide concentrations down the vertical axis of boulders of different size. (c) Vertical profiles normalized by diameter. 
(a)

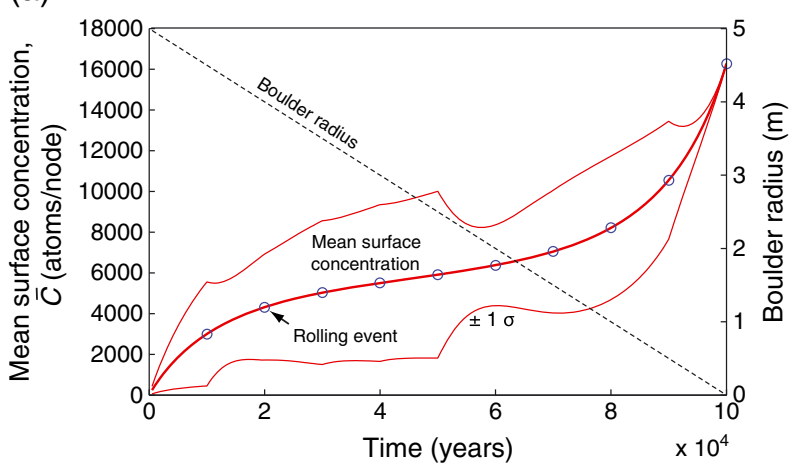

(b)

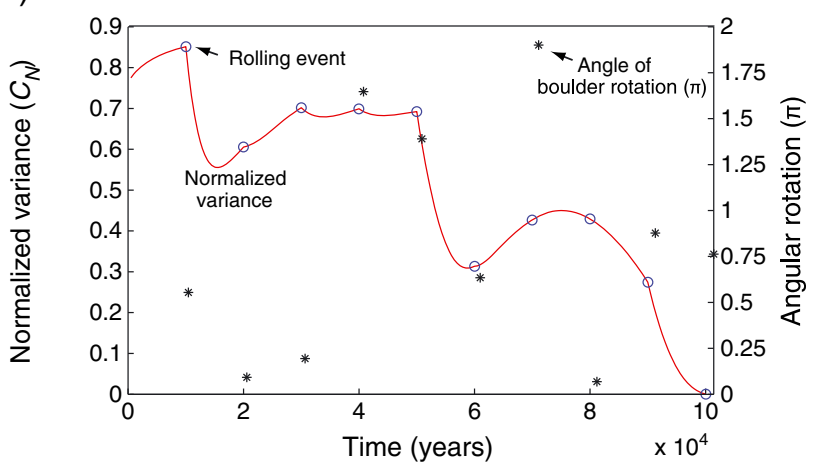

Figure 5. (a) Evolution of the mean and standard deviation nuclide concentration around a boulder (initial radius $5 \mathrm{~m}$ ) eroding at $0.05 \mathrm{~mm} / \mathrm{yr}$. Boulder radius is shown by dashed line, and 10 evenly spaced movement events by circles. (b) Evolution of normalized variance in nuclide concentration $\left(C_{N}\right)$ for the simulation in Figure 5a indicating the angular rotation for each movement event. Rotations of approximately $1 \pi$ have the greatest effect on $C_{N}$.

surface decreases quickly after a rolling event as a previously shielded section of the boulder is exposed at the top, balancing the variance in nuclide concentration. Figure $5 \mathrm{~b}$ shows that only rolling events that rotate the boulder approximately half a full rotation ( $\pi$ radians) significantly change the standard deviation. Eventually the newly exposed surface begins to accumulate sufficient nuclides to dominate the surface concentration, and the variance increases again before the next mobilization event.

[25] The trends of average nuclide concentration are sensitive to both boulder radius and erosion rate. Figure 6 shows the evolution of nuclides about boulders with a range of initial radii $\left(R_{0}=0.5-5.0 \mathrm{~m}\right)$ eroding under two different erosion rates. All simulations show the characteristic sinusoidal accumulation curve depicted in Figure 5. Boulders with the higher erosion rate exist for a shorter period of time and have consistently lower mean surface concentrations in comparison to boulders with the slower erosion rate. At a given time, boulders with a smaller initial radius have a higher mean surface concentration due to greater penetration of rays through the boulder and significant accumulation on the boulder's underside. For a specific erosion rate and final boulder size, there is surprisingly little variation in the final mean nuclide concentration around boulders whose initial radius is greater than $1.5 \mathrm{~m}$ and $t>20,000$ years (Figure 6).

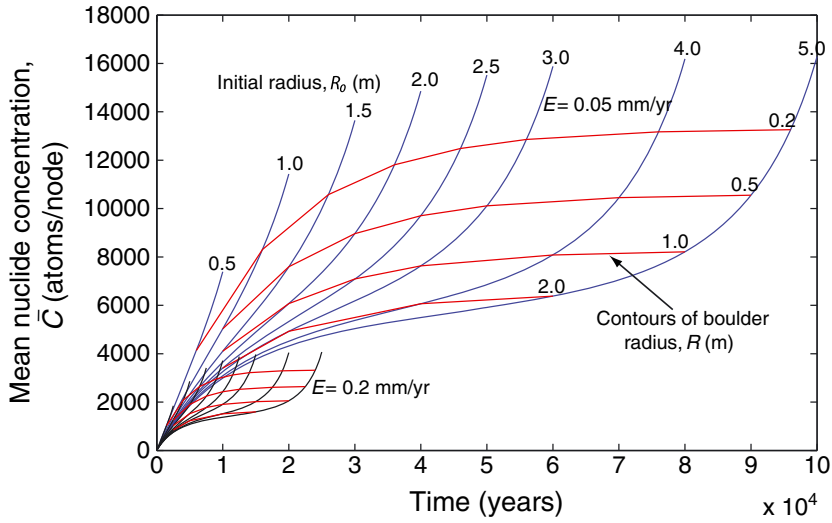

Figure 6. Evolution of mean surface exposure of boulders of varying diameter. Blue lines indicate erosion rate of $0.05 \mathrm{~mm} / \mathrm{yr}$, and black $0.2 \mathrm{~mm} / \mathrm{yr}$. Black lines represent the same initial boulder radii as the labeled blue lines. Red lines are contours of radius the boulders pass through as they erode, again replicated for the $0.2 \mathrm{~mm} / \mathrm{yr}$ erosion rate.

This indicates when a boulder reaches steady state erosion, such that rates of nuclide production and erosion are balanced, it is impossible to know its initial size without further information.

[26] In addition to the exposure age of a boulder, a key unknown is the frequency and number of mobilization events a boulder has experienced. To quantify variability of nuclide concentration around a boulder, we use the normalized variability of concentration $\left(C_{N}\right)$ around the boulder margin (standard deviation divided by the mean). In Figure 7, we explore the effect of mobilization frequency on a boulder with $2 \mathrm{~m}$ radius under two scenarios: no erosion and a constant erosion rate of $0.05 \mathrm{~mm} / \mathrm{yr}$. The mean concentration about the surface of the boulder is invariant to the number of mobilization events both for eroding and uneroding scenarios (Figure 7a). Mean nuclide concentration around the uneroding boulder increases linearly, whereas the rate of nuclide accumulation around the eroding boulder varies as a function of radius (e.g., Figure 5). Figure 7b illustrates the evolution of normalized variance for a $2 \mathrm{~m}$ radius boulder that is not eroding, but undergoing equally spaced movement events over a 40,000 year period for a range of total number of movement events $(n=0-15)$. The stable, uneroding boulder (Figure 7b) exhibits no change in normalized variance over that time. Boulders that do periodically rotate show a systematic decrease in $C_{N}$ with increasing movement events. At a given time, a boulder that has experienced a higher number of rotations will have a lower $C_{N}$, and similarly the temporal evolution of $C_{N}$ will decrease for an individual boulder. Figure 7c shows the same model set up as Figure 7b, but with the boulder radially eroding at $0.05 \mathrm{~mm} / \mathrm{yr}$. The stable eroding boulder (Figure 7c) experiences a gradual reduction in normalized variance as the radius decreases, due to a reduction in self-shielding at smaller radii. Likewise, eroding boulders have a lower normalized variance than the noneroding case of Figure $7 \mathrm{~b}$ for the equivalent number of movement events.

[27] While these experiments are useful to explore the behavior of nuclide accumulation in boulders under specific conditions, to be broadly applicable in field settings, many 


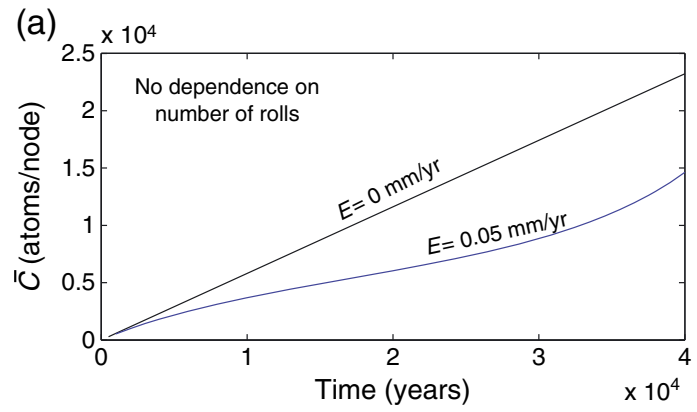

(b)

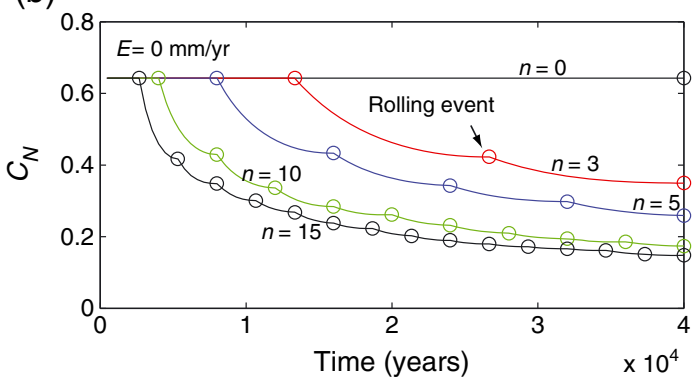

(c)

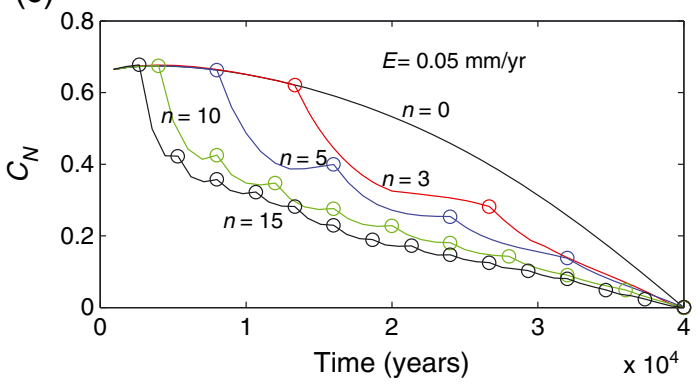

Figure 7. (a) Mean surface concentration $(\bar{C})$ of nuclides around the surface of an uneroding boulder, and a boulder eroding at $0.05 \mathrm{~mm} / \mathrm{yr}$ for a range of mobilizations over 40,000 years. Mean surface concentration is invariant of the number of mobilizations $(n)$ in both scenarios. (b) Normalized variance $\left(C_{N}\right)$ of an uneroding boulder and (c) a boulder eroding at $0.05 \mathrm{~mm} / \mathrm{yr}$ over 40,000 years. Circles indicate movement events. Plots show the mean of 200 simulations.

of the parameters (e.g., initial size, erosion rate, exposure duration) are unknown when sampling a boulder. In section 5 , we explore dimensional analysis to make this technique more universal.

\section{Dimensional Analysis}

[28] The accumulation of cosmogenic nuclides in a periodically mobile and eroding boulder can be described by the following variables: average erosion rate $(E,[\mathrm{~L} / \mathrm{T}])$, initial radius $\left(R_{0},[\mathrm{~L}]\right)$ measured radius $(R,[\mathrm{~L}])$, nuclide production rate $(P,[$ Atoms $/ \mathrm{M} / \mathrm{T}])$, mean surface concentration $(\bar{C},[$ Atoms $/ \mathrm{M}])$, standard deviation of surface concentration $\left(C_{\sigma},[\right.$ Atoms $\left./ \mathrm{M}]\right)$, movement recurrence interval $\left(r_{T},[\mathrm{~T}]\right)$, incremental and total exposure time $\left(t, t_{T},[\mathrm{~T}]\right)$, and true nuclide attenuation length $\left(z^{*}[\mathrm{~L}]\right)$. Using dimensional analysis, these parameters can be cast as five non-dimensional parameters:

$$
\begin{gathered}
T^{*}=\frac{t E}{z^{*}}=\frac{R_{0}-R}{z^{*}} \\
C^{*}=\frac{\bar{C} E}{P z^{*}}=\frac{\bar{C}\left(R_{0}-R\right)}{t P z^{*}} \\
C_{N}=\frac{C_{\sigma}}{\bar{C}} \\
n=\frac{t_{T}}{r_{T}}-1 \\
R^{*}=\frac{R}{z^{*}}
\end{gathered}
$$

where $T^{*}$ is the dimensionless time to erode one neutron flux $e$-folding length, or equivalently the total radial erosion length normalized by the neutron flux $e$-folding length, $C^{*}$ is normalized mean concentration around the boulder margin, $C_{N}$ is the normalized standard deviation of nuclide concentration, $n$ is the number of movement events a boulder has experienced, and $R^{*}$ is boulder radius normalized by the attenuation length. Through model simulations, we seek the functional relationships $C^{*}=f\left(T^{*}, n, R^{*}\right)$ and $C_{N}=f\left(T^{*}, n, R^{*}\right)$. This non-dimensionalization makes the results applicable to a wide range of parameters including differences in nuclide production rates and rock densities, for example.

\subsection{Mean Surface Concentration}

[29] A key relationship we want to explore is the evolution of mean nuclide concentration over time. Given the similarity of shapes for nuclide evolution in eroding boulders (e.g., Figure 6), we plot normalized mean concentration $\left(C^{*}\right)$ and dimensionless time $\left(T^{*}\right)$ for boulders of varying initial normalized radius $\left(R^{*}\right)$. Figure 8 illustrates the evolution of nuclide surface concentration around boulders with initial dimensionless radii $R^{*}=0.6-60$ (radius $0.5-50 \mathrm{~m}$ in basalt on Earth), shown by black lines. As in Figure 6, we show contours of where the boulders erode through a given radius $\left(R^{*}\right)$. This framework collapses variations in erosion rate evident in Figure 6 and is independent of the number of mobilization events (Figure 7a). The reference case, a flat eroding surface, is shown as the upper bound where steady state is $C^{*}=1$.

[30] As with all interpretations of cosmogenic exposure surface ages, there are two end-members. One scenario is a pristine uneroding surface, where nuclide concentration will simply reflect exposure age. Comparatively a surface which has eroded more than $\sim 2$ attenuation lengths will approach a steady state nuclide accumulation, and nuclide concentration will indicate erosion rate [e.g., Niedermann, 2002]. Between these end-members, nuclide concentrations reflect a combination of exposure age and erosion rate, as the concentration has not yet reached a steady state, and care needs to be taken interpreting concentrations. The same issues also apply to eroding boulders. To illustrate this, we identify distinct zones on Figure 8 where normalized mean concentration $\left(C^{*}\right)$ has distinct functional relationships to dimensionless time $\left(T^{*}\right)$ and dimensionless radius $\left(R^{*}\right)$, as reflected in the lines of equal $R^{*}$. Along a line of constant $R^{*}$, normalized mean concentration $\left(C^{*}\right)$ initially increases linearly as dimensionless time $\left(T^{*}\right)$ increases. In contrast, for a total radial erosion length that is greater than about three times the nuclide attenuation length (i.e., $T^{*} \geq 3$ ), the normalized mean concentration tends to a value that is independent of dimensionless time and solely 


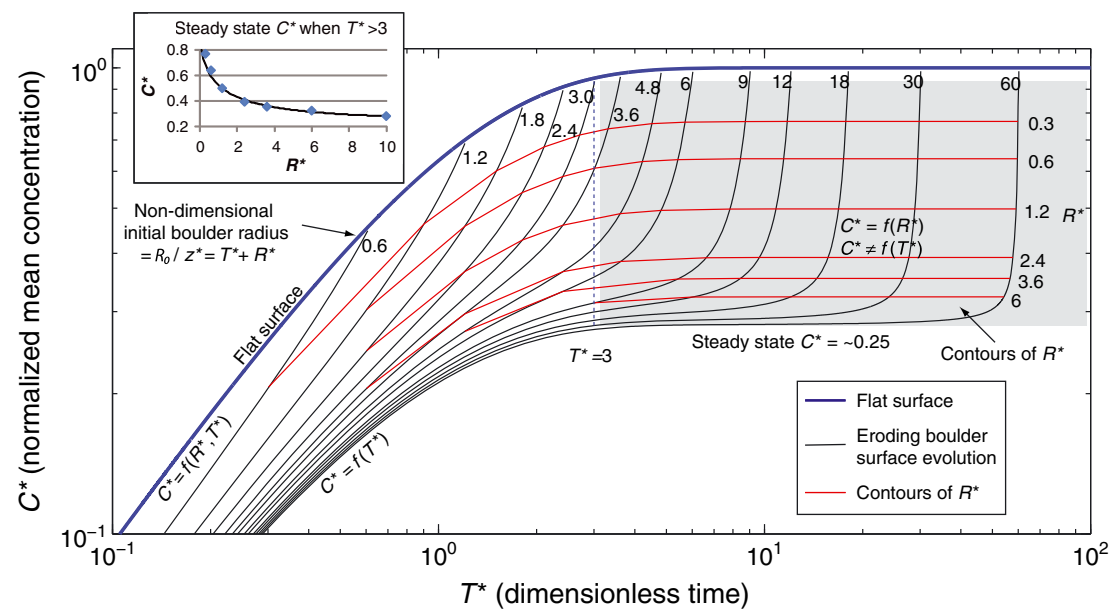

Figure 8. Dimensionless mean surface concentration $\left(C^{*}\right)$ and dimensionless time $\left(T^{*}\right)$ for a range of non-dimensional initial boulder radii $\left(R^{*}\right)$. Black lines indicate the evolution of individual boulders with a range of initial $R^{*}$. Red lines indicate contours of non-dimensional radius as the boulders erode, which reach steady state at $T^{*} \gtrsim 3$, shown by the zone of grey shading. $C^{*}$ and $T^{*}$ are independent of erosion rate and number of movements. Blue line is the reference case of a flat surface. Inset graph shows the dependence of $C^{*}$ on $R^{*}$ when boulder erosion reach steady state conditions (e.g., $T^{*}>3$ ), as described by equation (10).

dependent on dimensionless boulder size $\left(R^{*}\right)$. This is analogous to erosion of a flat surface that has reached steady state between nuclide accumulation and erosion [Cerling and Craig, 1994; Niedermann, 2002].

[31] In the region of parameter space where normalized mean concentration is independent of dimensionless time (i.e., $T^{*}>3$ ) (Figure 8), the normalized mean concentration $\left(C^{*}\right)$ has an exponential dependence on dimensionless radius $\left(R^{*}\right)$, following

$$
C^{*}=(1-A) \exp \left(-R^{* B}\right)+A
$$

$\left(R^{2}=0.99\right)$, where $A=0.25$ and $B=0.5$ are best fit parameters (Figure 8 inset). Equation (10) reproduces the expected findings of $C^{*}=1$ for a flat surface $\left(R^{*}=0\right)$ [e.g., Lal, 1991], and it converges to $C^{*}=0.25$ for large boulders $\left(R^{*}>6\right)$. We suspect that large boulders have a factor of four lower normalized mean concentration than a flat surface because of the relative surface area of a sphere $\left(4 \pi r^{2}\right)$ compared to the equivalent area projected on a horizontal plane $\left(\pi r^{2}\right)$. For smaller boulders (i.e., $R^{*}<6$ ), the normalized mean concentration $\left(C^{*}\right)$ increases exponentially towards the $C^{*}$ value of a flat surface $\left(C^{*}=1\right.$ for $\left.T^{*}>3\right)$. We suspect that the exponential dependence is due to greater penetration of rays completely through the boulder for smaller boulders and the exponential decal in flux intensity with depth. Where initial $R^{*}$ is less than $\sim 3$, the normalized mean concentration $\left(C^{*}\right)$ is dependent on both dimensionless time $\left(T^{*}\right)$ and dimensionless radius $\left(R^{*}\right)$; these boulders never approach an erosional steady state in surface nuclide concentration, as the initial radius is too small.

\subsection{Variance of Nuclide Concentration}

[32] To quantify the variability in nuclide concentration around the boulder surface as a proxy for number of mobilization events, as in Figure 7, we use the normalized variance of nuclide concentration $\left(C_{N}\right)$ around the margin of a boulder. We quantify $C_{N}$ as a function of mobilization number $(n)$ for a range of erosion scenarios and boulder diameter. Maximizing what we do know about a boulder, namely radius, which can be measured in the field, and the measureable statistics of nuclide concentration, in Figure 9 we explore the dependence of $C_{N}$ on normalized radius $\left(R^{*}\right)$ and dimensionless time $\left(T^{*}\right)$ for boulders experiencing different numbers of rolling events $(n)$. Each line on the graph represents equal exposure and erosion (i.e., constant $R^{*}$ and $\left.T^{*}\right)$, but with variable rolling events $(n)$, as opposed to the evolution of variance within an individual boulder over time (Figure 7). The plots reflect the mean of 200 simulations and variance among simulations results from randomness introduced in rolling position.

[33] Figure 9a shows the dependence of normalized variance $\left(C_{N}\right)$ on the number of rolling events $(n)$ for a range of final normalized boulder radii $\left(R^{*}\right)$ with a constant $T^{*}=1.2$. Normalized variance is strongly dependent on normalized boulder radius. Simulations with larger $R^{*}$ have consistently higher values of $C_{N}$, and a more gradual decay in $C_{N}$ with increasing rolling events. Simulations with the smallest dimensionless boulder radius $\left(R^{*}\right)$ have low normalized variance $\left(C_{N}\right)$, even at low numbers of mobilization events $(n)$, and $C_{N}$ has little dependence on increasing $n$. These trends occur because rays can easily penetrate the smaller boulders, and there is less potential to develop the strong asymmetry in exposure on different sections of the boulder required for large $C_{N}$.

[34] Comparatively, in Figure 9b, we explore the effect of varying the dimensionless time $\left(T^{*}\right)$ on a boulder with a fixed final normalized radius $\left(R^{*}\right)$ of 2 (equivalent to a radius of $1.7 \mathrm{~m}$ in a basalt boulder). There is little variation in the curves of $C_{N}$ where $T^{*}$ is less than 2. Simulations with higher values of $T^{*}$ show increasingly larger values of $C_{N}$ for a given number of rolling events, and the decay of $C_{N}$ with increasing $n$ is more gradual. This pattern was observed across all values of final $R^{*}$ analyzed $\left(1.2<R^{*}<3.6\right)$. 
(a)

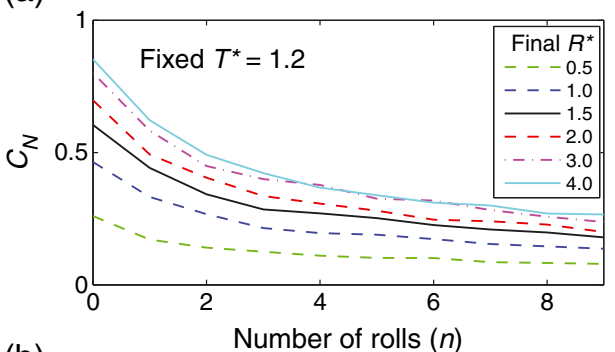

(b)

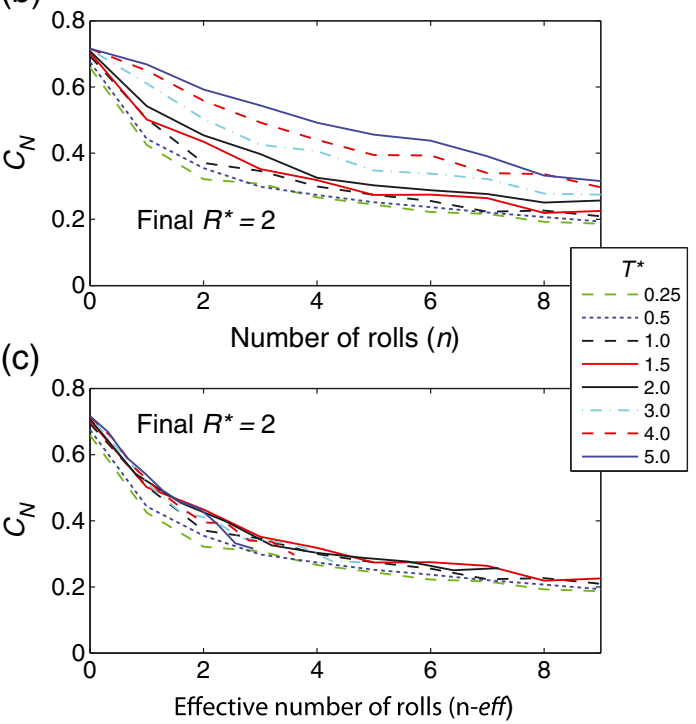

Figure 9. (a) Normalized variance of a boulder with fixed final normalized radius $\left(R^{*}\right)$. Each curve represents a constant dimensionless time $\left(T^{*}\right)$ of 1.2 (non-dimensional thickness of erosion) that has been removed from the boulder. (b) Normalized variance $\left(C_{N}\right)$ of boulders of constant final size $\left(R^{*}=2\right)$ that have undergone variable amounts of erosion $\left(T^{*}\right)$. Boulders with $T^{*}<2$ show little variance in $C_{N}$, whereas larger values of $T^{*}$ have larger $C_{N}$. (c) The effective number of roles $\left(n_{\text {eff }}\right.$, equation (11)) collapses the variation in larger values of $T^{*}$. Each experiment was repeated 200 times, and we show the mean value of $C_{N}$. For clarity we have not shown the variance in $C_{N}$ between the 200 simulations, but it is typically $0.05-0.1( \pm 1 \sigma)$.

[35] This shift to higher normalized variance in nuclide concentration $\left(C_{N}\right)$ for longer dimensionless time $\left(T^{*}\right)$ can be explained by the large radial thickness being removed for the same number of movement events. Where $T^{*}>2$, the final boulder surface has minimal nuclide build up over the initial rolls, as the interior of the boulder is shielded. Only over the final few rolls does it begin to experience the strong asymmetry of nuclide accumulation rates between the upper and lower ultimate surfaces, potentially resulting in high values of $C_{N}$. To incorporate this effect, we introduce the variable $T^{*}$ crit, which is a cutoff value of $T^{*}$ where the exponential decline of production rate becomes negligible. We adopt a value of $T^{*}$ crit of 1.5 , which approximates the transition in $T^{*}$ from where the lines of $C_{N}$ are tightly clustered, to where they deviate from the grouping (Figure 9b). We define the effective number of rolling events $\left(n_{\text {eff }}\right)$ as the number of rolling events that occurred during the time when significant concentrations of cosmogenic nuclides were accumulating in the rock that will become the final exposed surface of the boulder

$$
n_{\mathrm{eff}}=n\left(\frac{T^{*}{ }_{\mathrm{crit}}}{T^{*}}\right)
$$

[36] Recasting the results in Figure $9 \mathrm{~b}$ using $n_{\text {eff }}$ shows that the model results collapse to a single curve (Figure 9c). Thus, for boulders with very large $T^{*}, C_{N}$ will only record the more recent movement events $\left(n_{\text {eff }}\right)$.

\section{Discussion}

\subsection{Field Sampling}

[37] As discussed in section 3, our simulations show that at least 10 samples evenly distributed around the circumference of a boulder are needed to capture the true statistics of surface concentration to within 5\% (Figure 3). These results apply to boulders that rotate about a preferred axis, which should be targeted for field application. In field settings, these are most likely to be prolate spheroids or elliptical-shaped boulders, for example, boulders derived from columnar jointed basalt [e.g., Ehlmann et al., 2008]. Boulders which have unconstrained rolling behavior and can roll in any orientation are likely to show more variability in nuclide concentrations. Due to the stochastic nature of rolling imposed in our simulations, results presented are based in cases on averages of 200 repeat simulations. Model results that average fewer simulations in general show more noise, and our results indicate that approximately $5-10$ boulders that experienced similar transport may need to be measured to reproduce the trends in the model results. Together, this suggests that field applications may need to collect 50-100 samples, which represents a significant but tractable undertaking [DiBiase et al., 2010; Vassallo et al., 2011].

[38] From a practical viewpoint, as described above, settings which minimize the potential for boulders to spend significant time exposed on hillslopes should be sought. Rocks which are resilient to fragmentation and abrade slowly, rather than break into pieces, best reflect the modeled conditions of slow steady background erosion.

\subsection{Boulder Residence Time and Boulder Erosion Rate}

[39] Modeling the evolution of nuclides in a mobile and eroding boulder has revealed that it is possible, in certain cases, to elicit meaningful information about the transport, erosion, and mobilization history of boulders.

[40] Given the relationship between normalized mean nuclide concentration $\left(C^{*}\right)$ and dimensionless time $\left(T^{*}\right)$ (Figure 8 ), where $T^{*}$ is $\$ 3, C^{*}$ depends on both dimensionless boulder radius $\left(R^{*}\right)$ and dimensionless time $\left(T^{*}\right)$, analogous to a flat surface that has not yet reached an erosional steady state in nuclide concentration. Without an independent constraint on erosion rate $(E)$ or initial boulder radius $\left(R_{0}\right)$, it is not possible to constrain total boulder residence time $\left(t_{T}\right)$ as the surface concentration has not yet reached steady state and $\bar{C}=f\left(t_{T}, E, R_{0}\right)$. However, with knowledge of one of these variables, discussed below, the other two can be constrained.

[41] In comparison, where $T^{*}>3$, dimensionless mean concentration $\left(C^{*}\right)$ is independent of dimensionless time 
$\left(T^{*}\right)$, and the erosion rate can be determined. On a flat surface eroding at steady state, the erosion rate can be calculated from equation (5) with $C^{*}=1$, which can be rewritten in a standard form [e.g., Lal, 1991] as

$$
E=z^{*}\left(\frac{P}{C}\right)
$$

[42] For boulders, a generic version of equation (12) can be formulated by incorporating the steady state $C^{*}$ for the boulder size of interest (i.e., equation (6)), as

$$
E=\frac{C^{*} z^{*} P}{\bar{C}}
$$

[43] Thus, the boulder erosion rate can be determined from equation (13) with the known values of $z^{*}, P$, nuclide concentration measurements to determine $\bar{C}$, and the normalized mean concentration $\left(C^{*}\right)$, which can be found from equation (10) and a readily made field measurement of boulder radius (if $T^{*}>3$ ). With $E$ determined, and assuming that $T^{*}=3$ as a minimum bound, we can solve equation (5) to determine a minimum boulder residence time. To obtain the true boulder residence time $\left(t_{T}\right)$ rather than a minimum estimate, knowledge of the initial radius $\left(R_{0}\right)$ is required for a direct measure of $T^{*}$ (equation (5)). In such a case, both $T^{*}$ and $R^{*}$ can be calculated directly from equations (5) and (9), which uniquely constrains $C^{*}$ from Figure 8 (regardless of whether the mean nuclide concentration is at an erosional steady state). In this case, the boulder erosion rate and residence time can be determined from equations (13) and (5), respectively, given nuclide concentration measurements to determine $\bar{C}$, and known $z^{*}$ and $P$.

[44] It is not possible to know if $T^{*}>3$ or $<3$ without independent estimates of initial boulder size $\left(R_{0}\right)$ or erosion rate $(E)$. Although it is difficult to assess $R_{0}$ and $E$ directly, it may be possible to constrain them with field data. Initial boulder sizes are likely limited by the fracture characteristics of the bedrock, and a survey of large boulder sizes in the upper reaches of the channel of interest will provide constraint on the characteristic sizes of boulders as they enter a channel network. There are very little data documenting how fast boulders erode [Seidl et al., 1997]. The large boulders we are modeling here likely erode at a similar rate to bedrock adjacent to the channel, as they will experience the same flooding effects, suspended load, and ambient environmental erosion factors (e.g., cycles of wetting and drying) [Matmon et al., 2005]. In some scenarios, the exposure age of the rock may be independently known; for example, from a dated lava flow, or a large landslide or rockfall of known age. In this scenario, it is possible to use the relationship between $C^{*}$ and $T^{*}$ to determine the boulder erosion rate and the initial size from the boulder residence time.

\subsection{Mobilization Frequency}

[45] We can clearly distinguish a permanently stable boulder from one that has experienced multiple movement events, whereupon different faces of the boulder have been intermittently facing upright (Figures 7 and 9). This presents the simplest application of measuring multiple samples from one boulder and has clear application to geomorphic studies where cosmogenic exposure age interpretations assume the boulder has been immobile with little inheritance, such as dating boulders from glacial deposits [Hallet and Putkonen, 1994] or megaflood deposits [Cerling et al., 1994; Lamb et al., 2008].

[46] We have explored the potential for the variance of nuclide concentration around the margin of a boulder to be used to retrodict boulder transport history. The results show normalized variance decreasing predictably with the number of mobilization events (Figure 9). It would be difficult to distinguish the exact number of rolls a boulder has experienced for $n \gtrsim 4$ due to the inherent randomness of rolling, and the tendency for $C_{N}$ to rapidly approach an equilibrium value (Figure 9). We note that noble gas mass spectrometers have precision of $\sim 5 \%$ ( $1 \sigma$ standard deviation) [Amidon et al., 2009], which when combined with the uncertainty in capturing standard deviation from 10 samples (5\%), indicates that measurements of $C_{N}$ below approximately 0.1 will potentially reflect analytical error and sampling uncertainty rather than true variation. However, it should be possible to differentiate between boulders that have moved once or twice, which have a relatively high $C_{N}$, from those that have been mobilized tens of times, where the $C_{N}$ is uniformly low.

[47] Final boulder size does exert a significant influence on the magnitude of $C_{N}$, with larger diameters showing greater sensitivity of $C_{N}$ to the number of mobilizing events (Figure 9a). This is due to the relationship between boulder diameter and the $e$-folding length of the ray intensity decay, such that there is little potential for relatively small boulders to develop a strong asymmetry between top and bottom surfaces. In any field application, it would therefore be advisable to target larger boulders ( $>1 \mathrm{~m}$ radius) to ensure greatest sensitivity of $C_{N}$ on $n$.

[48] While it is desirable to analyze a boulder with a large dimensionless erosion time $\left(T^{*}\right)$ to establish an erosion rate, at high values of $T^{*}$ much of the history of the boulder's early movements are undetectable on the sampled surface. Therefore to establish a total mobilization history, our results indicate it is preferable to sample boulders with $T^{*} \lesssim 1.5$. In this case the boulder movement recurrence interval can be calculated from equation (8) as $r_{T}=t_{T} / n+1$, provided that the boulder residence time $\left(t_{T}\right)$ can be found from measurements of $\bar{C}$ as discussed in section 6.1. Where $T^{*} \gtrsim 1.5, C_{N}$ will largely record movement history within the dimensionless time $T^{*}$ crit. In some scenarios, this recent transport history may be more valuable than the entire transport history of the boulder. In this case, the effective number of movements can be tied to a boulder erosion rate through measurement of $\bar{C}$, or a minimum recurrence interval using $r_{T}=t / n_{\mathrm{eff}}+1$.

\subsection{Application of Mobilization Frequency to Flood Recurrence}

[49] Large boulders in fluvial systems are most commonly mobilized by extreme flooding or debris flow events, where flows that impart high shear stresses can rotate and dislodge boulders. Hydraulic calculations incorporating boulder size and channel geometry can be used to reconstruct the flood discharges needed to move a boulder with a given geometry [Baker, 1973; Costa, 1983; Williams, 1983; Carling, 1996; Lamb et al., 2008; Turowski et al., 2009], and this approach 


\section{MACKEY AND LAMB: BOULDER HISTORY FROM COSMOGENIC NUCLIDES}

is widely used for paleo-hydraulic reconstruction of geologically important floods (e.g., Missoula Floods [Bretz, 1923; Baker, 1973], Bonneville Flood [O'Connor, 1993]). These studies are generally applied to extreme, single event floods (e.g., glacial outburst events), where large boulders have been mobilized once and are subsequently immobile. We suggest that by extension, if the mobilization frequency $\left(r_{T}\right)$ of a large boulder can be established, then it may serve as a useful proxy for large-magnitude, low-frequency meteorological flood events, rather than simply the time of the most recent event. Presently, the recurrence interval of floods in the $10^{3}-10^{4}$ year recurrence range is very difficult to constrain directly [Griffis and Stedinger, 2007]. Predicting rare, large magnitude floods typically relies on statistical extrapolation of historical records [Malamud and Turcotte, 2006], although this approach attracts considerable uncertainty, given that measurement records seldom exceed 100 years. Sampling multiple boulders to independently establish a characteristic erosion rate (e.g., for boulders with $T^{*}>3$ ), in concert with other boulders where $T^{*}<3$ could be used to establish the history of a population of boulders of different size and erosion states. If different-sized boulders have a different recurrence interval, it could be used to retrodict the history of paleofloods of different magnitudes where there is a threshold between flood stage and the size of boulders mobilized.

\section{Conclusion}

[50] We have explored the potential for cosmogenic nuclides to constrain a boulder's transport and erosion history, via taking multiple samples around the boulder margin. This approach can clearly discriminate between a boulder which has been stable during exposure and from one which has experienced multiple movement events. Further, with additional information relating to erosion rate or initial boulder diameter constrained by field observations or additional data, the minimum time a boulder has been exposed to cosmic rays can be derived independently of the number of movement events it has experienced. For cases of minimal inheritance and constant erosion, the normalized variance of nuclide concentration around a boulder's margin decreases with the number of mobilization events, and this ratio can be used to constrain the number of times a boulder has moved, for up to approximately four events, beyond which the ratio approaches a constant value. Given the dimensionless framework, these results can be readily applied to different lithologies where rock density can vary, and for changes in production rates governed by location and the nuclide and mineral of interest. Results may be applicable for a wide range of cases including verifying stability (e.g., moraine age dating) or determining the frequency of rare floods or debris flows; however, tens of samples are needed to ensure a statistically significant result.

[51] Acknowledgments. This work was supported by NSF grants EAR-0922199 and EAR-1204375 to MPL. We thank Ken Farley for helpful discussions. Comments from Joel Johnson, Simon Brocklehurst, Alex Densmore, and two anonymous reviewers improved this manuscript.

\section{References}

Aciego, S. M., D. J. DePaolo, B. M. Kennedy, M. P. Lamb, K. W. W. Sims, and W. E. Dietrich (2007), Combining $\left[\mathrm{He}^{3-}\right]$ cosmogenic dating with
$\mathrm{U}-\mathrm{Th} / \mathrm{He}$ eruption ages using olivine in basalt, Earth Planet. Sci. Lett., 254(3-4), 288-302.

Amidon, W. H., and K. A. Farley (2011), Cosmogenic $\mathrm{He}^{3-}$ production rates in apatite, zircon and pyroxene inferred from Bonneville flood erosional surfaces, Quat. Geochronol., 6(1), 10-21.

Amidon, W. H., D. H. Rood, and K. A. Farley (2009), Cosmogenic He-3 and $\mathrm{Ne}-21$ production rates calibrated against Be-10 in minerals from the Coso volcanic field, Earth Planet. Sci. Lett., 280(1-4), 194-204.

Attal, M., and J. Lavé (2009), Pebble abrasion during fluvial transport: Experimental results and implications for the evolution of the sediment load along rivers, J. Geophys. Res., 114(F4), F04023.

Baker, V. R. (1973), Paleohydrology and sedimentology of the Lake Missoula flooding in eastern Washington, Geol. Soc. Am., Spec. Pap., 144, 79 .

Balco, G., M. D. Purvance, and D. H. Rood (2011), Exposure dating of precariously balanced rocks, Quat. Geochronol., 6, 295-303.

Behr, W. M., et al. (2010), Uncertainties in slip-rate estimates for the Mission Creek strand of the southern San Andreas fault at Biskra Palms Oasis, southern California, Geol. Soc. Am. Bull., 122(9-10), 1360-1377.

Bhandari, N., et al. (1993), Depth and size dependence of cosmogenic nuclide production-rates in stony meteoroids, Geochim. Cosmochim. Ac., 57(10), 2361-2375.

Blard, P. H., and K. A. Farley (2008), The influence of radiogenic He-4 on cosmogenic He-3 determinations in volcanic olivine and pyroxene, Earth Planet. Sci. Lett., 276(1-2), 20-29.

Blum, M. D., and T. E. Tornqvist (2000), Fluvial responses to climate and sea-level change: A review and look forward, Sedimentology, 47, 2-48.

Bretz, J. H. (1923), The channeled scablands of the Columbia Plateau, J. Geol., 31(8), 617-649.

Briner, J. P. (2009), Moraine pebbles and boulders yield indistinguishable Be-10 ages: A case study from Colorado, USA, Quat. Geochronol., 4 (4), 299-305.

Buffington, J. M., D. R. Montgomery, and H. M. Greenberg (2004), Basinscale availability of salmonid spawning gravel as influenced by channel type and hydraulic roughness in mountain catchments, Can. J. Fish. Aquat. Sci., 61(11), 2085-2096.

Carling, P. A. (1983), Threshold of coarse sediment transport in broad and narrow natural streams, Earth Surf. Process. Landforms, 8, 1-18.

Carling, P. A. (1996), Morphology, sedimentology and paleohydraulic significance of large gravel dunes: Altai Mountains, Siberia, Sedimentology, 43, 647-664.

Carling, P. A., M. Hoffman, and A. S. Blatter (2002), Initial motion of boulders in bedrock channels, in Ancient Floods, Modern Hazards: Principles and Applications of Paleoflood Hydrology, edited by P. K. House, R. H. Webb, V. R. Baker, and D. R. Levish, American Geophysical Union, Washington DC.

Carretier, S., and V. Regard (2011), Is it possible to quantify pebble abrasion and velocity in rivers using terrestrial cosmogenic nuclides?, J. Geophys. Res., 116(F4), F04003.

Carretier, S., V. Regard, and C. Soual (2009), Theoretical cosmogenic nuclide concentration in river bed load clasts: Does it depend on clast size?, Quat. Geochronol., 4(2), 108-123.

Cerling, T. E., and H. Craig (1994), Geomorphology and in-situ cosmogenic isotopes, Annu. Rev. Earth Planet. Sci., 22, 273-317.

Cerling, T. E., R. J. Poreda, and S. L. Rathburn (1994), Cosmogenic He-3 and Ne-21 age of the Big-Lost-River-Flood, Snake-River-Plain, Idaho, Geology, 22(3), 227-230.

Costa, J. E. (1983), Paleohydraulic reconstruction of flash-flood peaks from boulder deposits in the Colorado Front Range, Geol. Soc. Am. Bull., 94 (8), 986-1004.

DiBiase, R. A., K. X. Whipple, A. M. Heimsath, and W. B. Ouimet (2010), Landscape form and millennial erosion rates in the San Gabriel Mountains, CA, Earth Planet. Sci. Lett., 289(1-2), 134-144.

Douglass, D. C., B. S. Singer, M. R. Kaplan, D. M. Mickelson, and M. W. Caffee (2006), Cosmogenic nuclide surface exposure dating of boulders on lastglacial and late-glacial moraines, Lago Buenos Aires, Argentina: Interpretive strategies and paleoclimate implications, Quat. Geochronol., 1(1), 43-58.

Dunai, T. J. (2010), Cosmogenic Nuclides: Principles, Concepts and Applications in the Earth Surface Sciences, 187 pp., Cambridge University Press, Cambridge.

Dunne, J., D. Elmore, and P. Muzikar (1999), Scaling factors for the rates of production of cosmogenic nuclides for geometric shielding and attenuation at depth on sloped surfaces, Geomorphology, 27(1-2), 3-11.

Eaton, E. C. (1935), Flood and erosion control problems and their solution, Trans. Am. Soc. Civ. Eng., 101, 1302-1330.

Ehlmann, B. L., H. A. Viles, and M. C. Bourke (2008), Quantitative morphologic analysis of boulder shape and surface texture to infer environmental history: A case study of rock breakdown at the Ephrata Fan, Channeled Scabland, Washington, J. Geophys. Res., 113(F2). 


\section{MACKEY AND LAMB: BOULDER HISTORY FROM COSMOGENIC NUCLIDES}

Frankel, K. L., et al. (2007), Cosmogenic Be-10 and Cl-36 geochronology of offset alluvial fans along the northern Death Valley fault zone: Implications for transient strain in the eastern California shear zone, J. Geophys. Res., 112(B6), 18.

Gayer, E., S. Mukhopadhyay, and B. J. Meade (2008), Spatial variability of erosion rates inferred from the frequency distribution of cosmogenic He-3 in olivines from Hawaiian river sediments, Earth Planet. Sci. Lett., 266 (3-4), 303-315.

Goehring, B. M., M. D. Kurz, G. Balco, J. M. Schaefer, J. Licciardi, and N. Lifton (2010), A reevaluation of in situ cosmogenic He-3 production rates, Quat. Geochronol., 5(4), 410-418.

Gosse, J. C., and F. M. Phillips (2001), Terrestrial in situ cosmogenic nuclides: Theory and application, Quat. Sci. Rev., 20(14), 1475-1560.

Graf, T., H. Baur, and P. Signer (1990), A model for the production of cosmogenic nuclides in chondrites, Geochim. Cosmochim. Ac., 54(9), 2521-2534.

Granger, D. E., J. W. Kirchner, and R. Finkel (1996), Spatially averaged long-term erosion rates measured from in situ-produced cosmogenic nuclides in alluvial sediment, J. Geol., 104(3), 249-257.

Granger, D. E., C. S. Riebe, J. W. Kirchner, and R. C. Finkel (2001), Modulation of erosion on steep granitic slopes by boulder armoring, as revealed by cosmogenic $26 \mathrm{Al}$ and $10 \mathrm{Be}$, Earth Planet. Sci. Lett., 186 (2), 269-281.

Griffis, V. W., and J. R. Stedinger (2007), Evolution of flood frequency analysis with Bulletin 17, J. Hydrol. Eng., 12(3), 283-297.

Hallet, B., and J. Putkonen (1994), Surface dating of dynamic landformsYoung boulders on aging moraines, Science, 265(5174), 937-940.

Heimsath, A. M., R. A. DiBiase, and K. X. Whipple (2012), Soil production limits and the transition to bedrock-dominated landscapes, Nat. Geosci., 5 (3), 210-214.

Heyman, J., A. P. Stroeven, J. M. Harbor, and M. W. Caffee (2011), Too young or too old: Evaluating cosmogenic exposure dating based on an analysis of compiled boulder exposure ages, Earth Planet. Sci. Lett., 302(1-2), 71-80.

Howard, A. (1998), Long profile development of bedrock channels: Interaction of weathering, mass wasting, bed erosion, and sediment transport, in Rivers Over Rock: Fluvial Processes in Bedrock Channels, edited by K. J. Tinker and E. E. Wohl, pp. 297-319, American Geophysical Union, Washington D.C

Johnson, J. P. L., K. X. Whipple, L. S. Sklar, and T. C. Hanks (2009), Transport slopes, sediment cover, and bedrock channel incision in the Henry Mountains, Utah, J. Geophys. Res., 114(F2), F02014.

Johnston, C. E., E. D. Andrews, and J. Pitlick (1998), In situ determination of particle friction angles of fluvial gravels, Water Resour. Res., 34(8), 2017-2030.

Kelsey, H. M. (1978), Earthflows in Franciscan Melange, Van Duzen River Basin, California, Geology, 6(6), 361-364.

Kodama, Y. (1994), Experimental-study of abrasion and its role in producing downstream fining in gravel-bed rivers, J. Sediment. Res. Sect. A-Sediment. Petrol. Process., 64(1), 76-85.

Kondolf, G. M., and M. G. Wolman (1993), The sizes of salmonid spawning gravels, Water Resour. Res., 29(7), 2275-2285.

Kurz, M. D. (1986), In situ production of terrestrial cosmogenic helium and some applications to geochronology, Geochim. Cosmochim. Ac., 50(12), 2855-2862.

Lal, D. (1991), Cosmic-ray labeling of erosion surfaces - In situ nuclide production-rates and erosion models, Earth Planet. Sci. Lett., 104(2-4) 424-439.

Lal, D. (1995), On cosmic-ray exposure ages of terrestrial rocks: A suggestion, Radiocarbon, 37(3), 889-898.

Lal, D., and J. Chen (2005), Cosmic ray labeling of erosion surfaces II: Special cases of exposure histories of boulders, soils and beach terraces, Earth Planet. Sci. Lett., 236(3-4), 797-813.

Lamb, M. P., W. E. Dietrich, S. M. Aciego, D. J. DePaolo, and M. Manga (2008), Formation of Box Canyon, Idaho, by megaflood: Implications for seepage erosion on Earth and Mars, Science, 320(5879), 1067-1070.

Lamb, M. P., W. E. Dietrich, and L. S. Sklar (2008), A model for fluvial bedrock incision by impacting suspended and bed load sediment, J. Geophys. Res., 113(F3).

Lamb, M. P., W. E. Dietrich, and J. G. Venditti (2008), Is the critical Shields stress for incipient sediment motion dependent on channel-bed slope?, J. Geophys. Res., 113(F2), F02008.

Lamb, M. P., and M. A. Fonstad (2010), Rapid formation of a modern bedrock canyon by a single flood event, Nat. Geosci., 3(7), 477-481.

Licciardi, J. M., M. D. Kurz, P. U. Clark, and E. J. Brook (1999), Calibration of cosmogenic He-3 production rates from Holocene lava flows in Oregon, USA, and effects of the Earth's magnetic field, Earth Planet. Sci. Lett., 172(3-4), 261-271.

Mackey, B. H., and M. P. Lamb (2010), Modeling the evolution of in situ cosmogenic nuclide concentrations in mobile and eroding boulders - Applications to channel incision and flood frequency analysis, EOS Trans. $A G U, E P 41 B-0703$.

Malamud, B. D., and D. L. Turcotte (2006), The applicability of power-law frequency statistics to foods, J. Hydrol., 322(1-4), 168-180.

Margerison, H. R., W. M. Phillips, F. M. Stuart, and D. E. Sugden (2005), Cosmogenic ${ }^{3} \mathrm{He}$ concentrations in ancient flood deposits from the Coombs Hills, northern Dry Valleys, East Antarctica: Interpreting exposure ages and erosion rates, Earth Planet. Sci. Lett., 230(1-2), 163-175.

Marshall, J. A., and L. S. Sklar (2012), Mining soil databases for landscapescale patterns in the abundance and size distribution of hillslope rock fragments, Earth Surf. Process. Landforms, 37(3), 287-300.

Masarik, J., and R. Wieler (2003), Production rates of cosmogenic nuclides in boulders, Earth Planet. Sci. Lett., 216(1-2), 201-208.

Masarik, J., D. Kollar, and S. Vanya (2000), Numerical simulation of in situ production of cosmogenic nuclides: Effects of irradiation geometry, $\mathrm{Nucl}$. Instrum. Methods Phys. Res., Sect. B, 172, 786-789.

Matmon, A., D. P. Schwartz, R. Finkel, S. Clemmens, and T. Hanks (2005), Dating offset fans along the Mojave section of the San Andreas fault using cosmogenic Al-26 and Be-10, Geol. Soc. Am. Bull., 117(5-6), 795-807.

Molnar, P., and P. England (1990), Late Cenozoic uplift of mountain ranges and global climate change: Chicken or egg?, Nature, 346(6279), 29-34.

Montgomery, D. R., T. B. Abbe, J. M. Buffington, N. P. Peterson, K. M. Schmidt, and J. D. Stock (1996), Distribution of bedrock and alluvial channels in forested mountain drainage basins, Nature, 381(6583), 587-589.

Muzikar, P. (2008), Cosmogenic nuclide concentrations in episodically eroding surfaces: Theoretical results, Geomorphology, 97(3-4), 407-413.

Nelson, P. A., J. G. Venditti, W. E. Dietrich, J. W. Kirchner, H. Ikeda, F. Iseya, and L. S. Sklar (2009), Response of bed surface patchiness to reductions in sediment supply, J. Geophys. Res., 114(F2), F02005.

Niedermann, S. (2002), Cosmic-ray-produced noble gases in terrestrial rocks: Dating tools for surface processes, in Noble Gases in Geochemistry and Cosmochemistry, edited by D. Porcelli, C. J. Ballentine and R. Wieler, pp. 731-784, Mineralogical Soc America, Washington.

Nishiizumi, K., E. L. Winterer, C. P. Kohl, J. Klein, R. Middleton, D. Lal, and J. R. Arnold (1989), Cosmic-ray production-rates of Be-10 and Al-26 in quartz from glacially polished rocks, J. Geophys. Res., 94(B12), 17907-17915.

O'Connor, J. E. (1993), Hydrology, Hydraulics, and Geomorphology of the Bonneville Flood, Geological Society of America, Boulder, CO.

Parker, G., and P. C. Klingeman (1982), On why gravel bed streams are paved, Water Resour. Res., 18(5), 1409-1423.

Putkonen, J., and T. Swanson (2003), Accuracy of cosmogenic ages for moraines, Quat. Res., 59(2), 255-261.

Putnam, A. E., J. M. Schaefer, D. J. A. Barrell, M. Vandergoes, G. H. Denton, M. R. Kaplan, R. C. Finkel, R. Schwartz, B. M. Goehring, and S. E. Kelley (2010), In situ cosmogenic Be-10 production-rate calibration from the Southern Alps, New Zealand, Quat. Geochronol., 5(4), 392-409.

Repka, J. L., R. S. Anderson, and R. C. Finkel (1997), Cosmogenic dating of fluvial terraces, Fremont River, Utah, Earth Planet. Sci. Lett., 152(1-4), 59-73.

van Rijn, L. C. (1984), Sediment transport: Part 2. Suspended load transport, J. Hydraul. Eng., 110(11), 1613-1641.

Ritz, J. F., E. T. Brown, D. L. Bourles, H. Philip, A. Schlupp, G. M. Raisbeck, F. Yiou, and B. Enkhtuvshin (1995), Slip rates along active faults estimated with cosmic-ray exposure dates-Application to the Bogd Fault, Gobi-Altai, Mongolia, Geology, 23(11), 1019-1022.

Rogers, H. E., T. W. Swanson, and J. O. Stone (2012), Long-term shoreline retreat rates on Whidbey Island, Washington, USA, Quat. Res., 78(2), 315-322.

Schmeeckle, M. W., J. M. Nelson, and R. L. Shreve (2007), Forces on stationary particles in near-bed turbulent flows, J. Geophys. Res., 112 (F02003), doi:10.1029/2006JF000536.

Schmidt, S., R. Hetzel, J. Kuhlmann, F. Mingorance, and V. A. Ramos (2011), A note of caution on the use of boulders for exposure dating of depositional surfaces, Earth Planet. Sci. Lett., 302(1-2), 60-70.

Schumm, S. A., and M. A. Stevens (1973), Abrasion in place: A mechanism for rounding and size reduction of coarse sediments in rivers, Geology, 1 (1), 37-40.

Seidl, M. A., W. E. Dietrich, and J. W. Kirchner (1994), Longitudinal profile development into bedrock-An analysis of Hawaiian channels, J. Geol., 102(4), 457-474.

Seidl, M. A., R. C. Finkel, M. W. Caffee, G. B. Hudson, and W. E. Dietrich (1997), Cosmogenic isotope analyses applied to river longitudinal profile evolution: Problems and interpretations, Earth Surf. Process. Landforms, 22(3), 195-209.

Sklar, L. S., and W. E. Dietrich (1998), River longitudinal profiles and bedrock incision models: Stream power and the influence of sediment supply, in Rivers Over Rock: Fluvial Processes in Bedrock Channels, edited by K. J. Tinker and E. E. Wohl, pp. 237-260, American Geophysical Union, Washington D.C. 


\section{MACKEY AND LAMB: BOULDER HISTORY FROM COSMOGENIC NUCLIDES}

Sneed, E. D., and R. L. Folk (1958), Pebbles in the lower-Colorado-River, Texas. A study in particle morphogenesis, J. Geol., 66(2), 114-150.

Stirling, M. W., and R. Anooshehpoor (2006), Constraints on probabilistic seismic-hazard models from unstable landform features in New Zealand, Bull. Seismol. Soc. Am., 96(2), 404-414.

Swanson, T. W., and M. L. Caffee (2001), Determination of $36 \mathrm{Cl}$ production rates derived from the well-dated deglaciation surfaces of Whidbey and Fidalgo Islands, Washington, Quat. Res., 56(3), 366-382.

Turowski, J. M., E. M. Yager, A. Badoux, D. Rickenmann, and P. Molnar (2009), The impact of exceptional events on erosion, bedload transport and channel stability in a step-pool channel, Earth Surf. Process. Landforms, 34(12), 1661-1673.

Vassallo, R., J.-F. Ritz, and S. Carretier (2011), Control of geomorphic processes on $10 \mathrm{Be}$ concentrations in individual clasts: Complexity of the exposure history in Gobi-Altay range (Mongolia), Geomorphology, 135(1-2), 35-47.

Vassallo, R., et al. (2007), Transpressional tectonics and stream terraces of the Gobi-Altay, Mongolia, Tectonics, 26(5), TC5013.
Whipple, K. X. (2004), Bedrock rivers and the geomorphology of active orogens, Annu. Rev. Earth Planet. Sci., 32, 151-185.

Whipple, K. X., G. S. Hancock, and R. S. Anderson (2000), River incision into bedrock: Mechanics and relative efficacy of plucking, abrasion, and cavitation, Geol. Soc. Am. Bull., 112(3), 490-503.

Williams, G. P. (1983), Paleohydrological methods and some examples from Swedish fluvial environments. 1. Cobble and boulder deposits, Geogr. Ann. A., 65(3-4), 227-243.

Wohl, E. E. (1992), Bedrock benches and boulder bars-Floods in the Burdekin Gorge of Australia, Geol. Soc. Am. Bull., 104(6), 770-778.

Wolman, M. G., and J. P. Miller (1960), Magnitude and frequency of forces in geomorphic processes, J. Geol., 68(1), 54-74.

Yager, E. M., J. W. Kirchner, and W. E. Dietrich (2007), Calculating bed load transport in steep boulder bed channels, Water Resour. Res., 43(7), 24.

Yager, E. M., J. M. Turowski, D. Rickenman, and B. W. McArdell (2012), Sediment supply, grain protrusion, and bedload transport in mountain streams, Geophys. Res. Lett., 39(10), L10402. 